\title{
Oral appliances, position papers and sleep disorders
}

\author{
John A Fleetham MD FRCPC
}

$\mathrm{O}^{\mathrm{s}}$ structive sleep apnea (OSA) is a very common disorder that often causes excessive daytime sleepiness and adverse cardiovascular consequences. Continuous positive airway pressure (CPAP) has been available for more than 30 years and is the primary treatment for OSA. However, not every patient can or is prepared to use CPAP as a long-term treatment. There are several new alternative treatments for OSA. Nasal expiratory positive airway pressure (EPAP), marketed as 'Provent' (Ventus Medical, USA), will soon be available in Canada. EPAP is a mechanical valve applied to each nostril with a low inspiratory resistance and high expiratory resistance that splints open the upper airway. Prospective randomized controlled trials have demonstrated subjective and objective improvement with this treatment in patients with mild to severe OSA (1). Hypoglossal nerve stimulation counteracts the reduced upper airway muscle activity during sleep, which is fundamental to the pathogenesis of OSA. Although this concept is not new, recent randomized controlled trials have demonstrated favourable safety, efficacy and compliance with this approach, which warrants further study (2). Oral appliances (OAs) are well established as an alternative treatment for OSA, both as primary therapy and as an alternative for patients who are unwilling or unable to tolerate CPAP. OAs are a simple, reversible, quiet and cost-effective therapy for selected patients with OSA (3). The 1996 Canadian Thoracic Society (CTS) guidelines on the diagnosis and treatment of sleep disordered breathing in adults included six recommendations concerning OA treatment for OSA (4). Two recommendations specifically addressed the dental community. First, it was recommended that OA should be fitted by qualified dental practitioners who have undertaken special training in sleep disordered breathing. Second, it was recommended that patients initiated on treatment with an OA should be seen in follow-up by a qualified dental practitioner regularly during the first year and then every year thereafter to monitor treatment adherence, OA deterioration and oral health. In the current issue of the Canadian Respiratory Journal (CRJ), The Canadian Sleep Society (CSS) and the Canadian Academy of Dental Sleep Medicine (CADSM) position paper (5) (pages 307-309) emphasizes the importance of a team approach to OA treatment for OSA and provides treatment guidelines for dentists trained in dental sleep medicine. This position paper builds on recommendations from a previous literature review (6) and practice parameters published by the American Academy of Sleep Medicine (7). Physicians are experts in the diagnosis, consequences and treatment options for OSA. Dentists are experts in oral health and the selection and fitting of OAs. It is important that each professional group recognize their strengths and weaknesses and work collaboratively to treat OSA patients with OAs.

Over the past decade, under the leadership of Dr Louis-Philippe Boulet, the CTS has developed Canadian guidelines for a variety of respiratory diseases, which are available on the website (www. respiratoryguidelines.ca) and are updated regularly. To be credible, it is important that national guidelines or position papers be established by a rigorous process rather than the 'BOGSAT' process (ie, 'Bunch Of Guys or Gals Sitting Around a Table'), which has characterized some previous guidelines and position papers. All recent
CTS guidelines, including last year's diagnosis and treatment of sleep disordered breathing guideline update (8), were developed according to the 23-item Appraisal of Guidelines for Research and Evaluation (AGREE) instrument (9). This is the current gold standard in the appraisal of practice guidelines and specifies the questions, target population, target user, methodology, literature search strategy, study selection criteria and outcomes of interest for any guideline or position paper. The CSS and CADSM should strongly consider using the AGREE instrument for the development of future guideline and position papers.

Sleep disorders are very common, and up to $20 \%$ of the adult population will experience some form of sleep disorder. At least 90 different sleep disorders have been described and these are defined in the widely used International Classification of Sleep Disorders, produced by the American Academy of Sleep Medicine (10). Sleep is the period of greatest physiological disturbance in patients with respiratory disease. Furthermore, respiratory disease and its treatment can have a major impact on a patient's sleep quality and quality of life. As the prevalence and importance of sleep disorders and sleep apnea become more widely recognized, respirologists are being referred many more patients with sleep-related symptoms. It is important that respirologists fully understand the differential diagnosis and management of nonrespiratory sleep disorders. Sleep disorder medicine is considered to be a subspecialty in the United States; however, to date, applications to have it accepted as a subspecialty by the Royal College of Physicians and Surgeons of Canada (RCPSC) have been unsuccessful. Sleep disorder medicine is currently practiced in Canada by respirologists, psychiatrists, neurologists, otolaryngologists, internists and some family physicians. Respirology is one of the few specialities that has included mandatory training in sleep disorders in it's RCPSC training program. There remains an outstanding need for either a RCPSC diploma or certification in sleep disorder medicine

The CTS is an association of respirologists whose mission is to promote lung health by supporting the respiratory community through leadership, collaboration, research, learning and advocacy, and promoting the best respiratory practices in Canada. The CSS is an association of clinicians, scientists and technologists whose mission is to further the advancement and understanding of sleep and its disorders through scientific study and public awareness, as well as to promote and support the growth and quality of sleep disorder medicine in Canada. In 2010, the two societies jointly developed a position paper on the use of portable monitoring for the diagnosis of OSA in adults, which was published in the CRJ (11). The CSS/CADSM position paper published in the present issue is evidence of further collaboration between the CSS and CTS. The CRJ now has an Associate Editor, John Kimoff, with a primary focus on sleep-related papers. The CRJ is currently working on a memorandum of understanding with the CSS, which hopefully will expand the interest of the Canadian sleep community in the CRJ, attract more manuscript submissions related to sleep and lead to the publication of more original articles, rigorously developed CSS guidelines and position papers, as well as abstracts from their biannual meetings. 


\section{REFERENCES}

1. Berry RB, Kryger MH, Massie CA. A novel nasal expiratory positive airway pressure (EPAP) device for the treatment of obstructive sleep apnea: A randomized controlled trial. Sleep 2011;34:479-85.

2. Eastwood PR, Barnes M, Walsh JH, et al. Treating obstructive sleep apnea with hypoglossal nerve stimulation. Sleep 2011;34:1479-86.

3. Fleetham J, Almeida FR. Oral appliances. Eur Respir 2010;50:267-85.

4. Fleetham J, Ayas N, Bradley D, et al. Canadian Thoracic Society Guidelines: Diagnosis and treatment of sleep disordered breathing in adults. Can Respir J 2006;13:3817-92.

5. Gauthier L, Almeida F, Arcache P, et al. Position paper by Canadian dental sleep medicine professionals in managing obstructive sleep apnea and snoring with oral appliances. Can Respir J 2012;19:307-9.

6. Ferguson KA, Cartwright R, Rogers R, Schmidt-Nowara W. Oral appliances for snoring and sleep apnea: A review. Sleep 2006;29:244-62.
7. Kushida CA, Morgenthaler TI, Littner MR, et al. Practice parameters for the treatment of snoring and obstructive sleep apnea with oral appliances: An update for 2005. Sleep 2006;29:240-3.

8. Fleetham J, Ayas N, Bradley D, et al. Canadian Thoracic Society 2011 guideline update: Diagnosis and treatment of sleep disordered breathing. Can Respir J 2011;18:25-47.

9. Brouwers M, Kho ME, Browman GP, et al; for the AGREE Next Steps Consortium. AGREE II: Advancing guideline development, reporting and evaluation in healthcare. Can Med Assoc J 2010;182:E839-42.

10. American Academy of Sleep Medicine. International Classification of Sleep Disorders. Diagnostic and coding manual, 2nd edn. Westchester: American Academy of Sleep Medicine, 2007.

11. Blackman A, McGregor C, Dales, R, et al. Canadian Sleep Society/ Canadian Thoracic Society position paper on the use of portable monitoring for the diagnosis of obstructive sleep apnea/hypopnea in adults. Can Respir J 2010;17:229-32. 


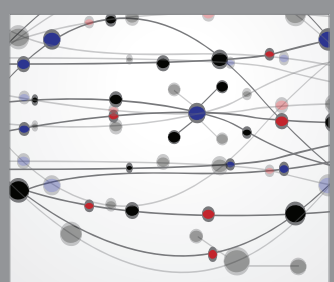

The Scientific World Journal
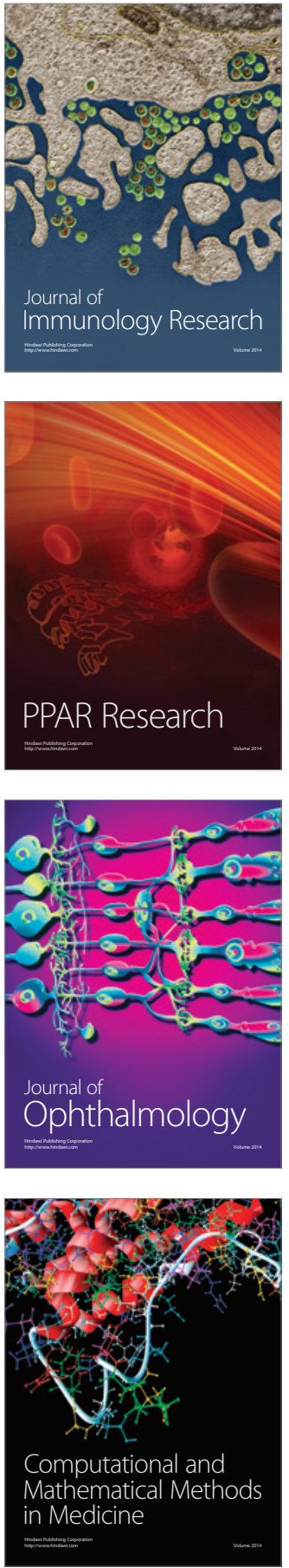

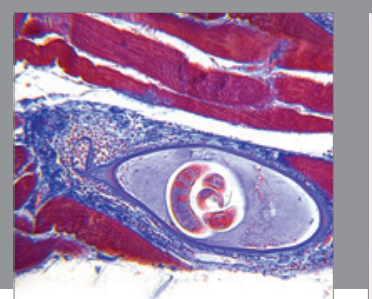

Gastroenterology Research and Practice

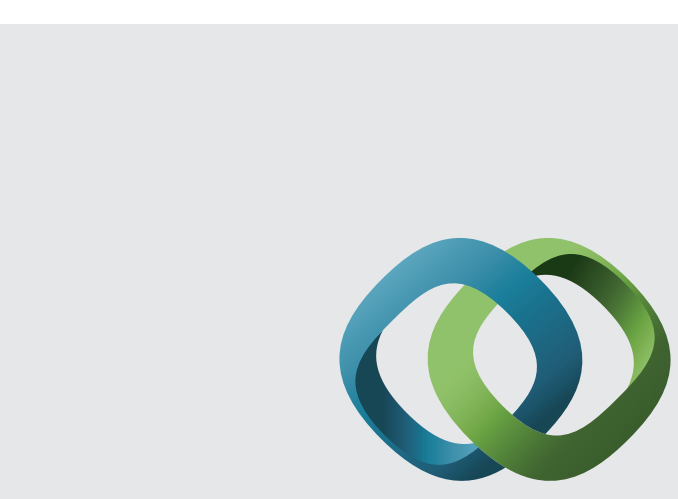

\section{Hindawi}

Submit your manuscripts at

http://www.hindawi.com
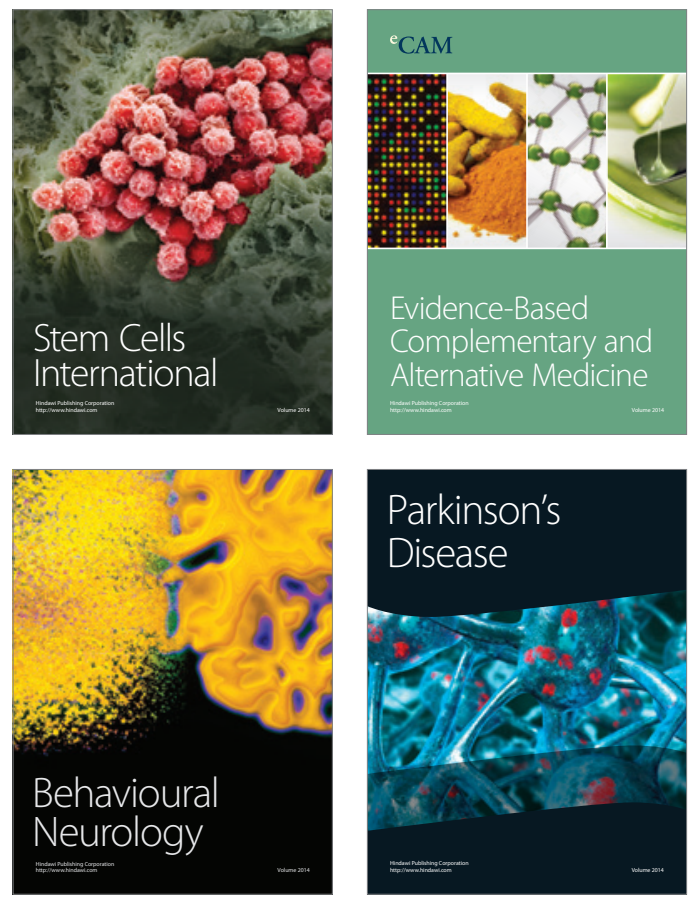
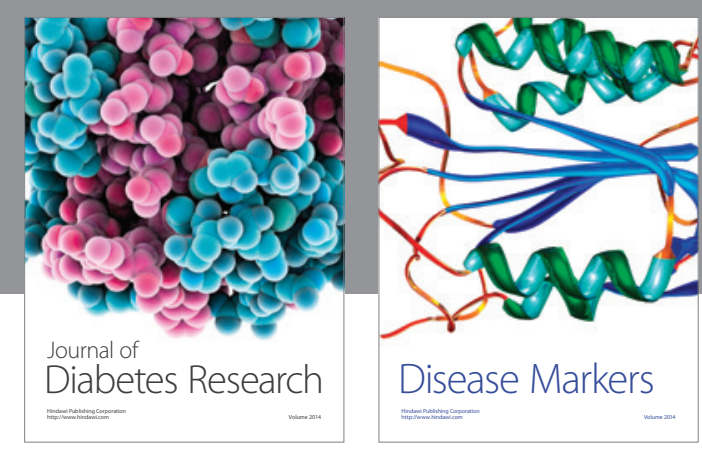

Disease Markers
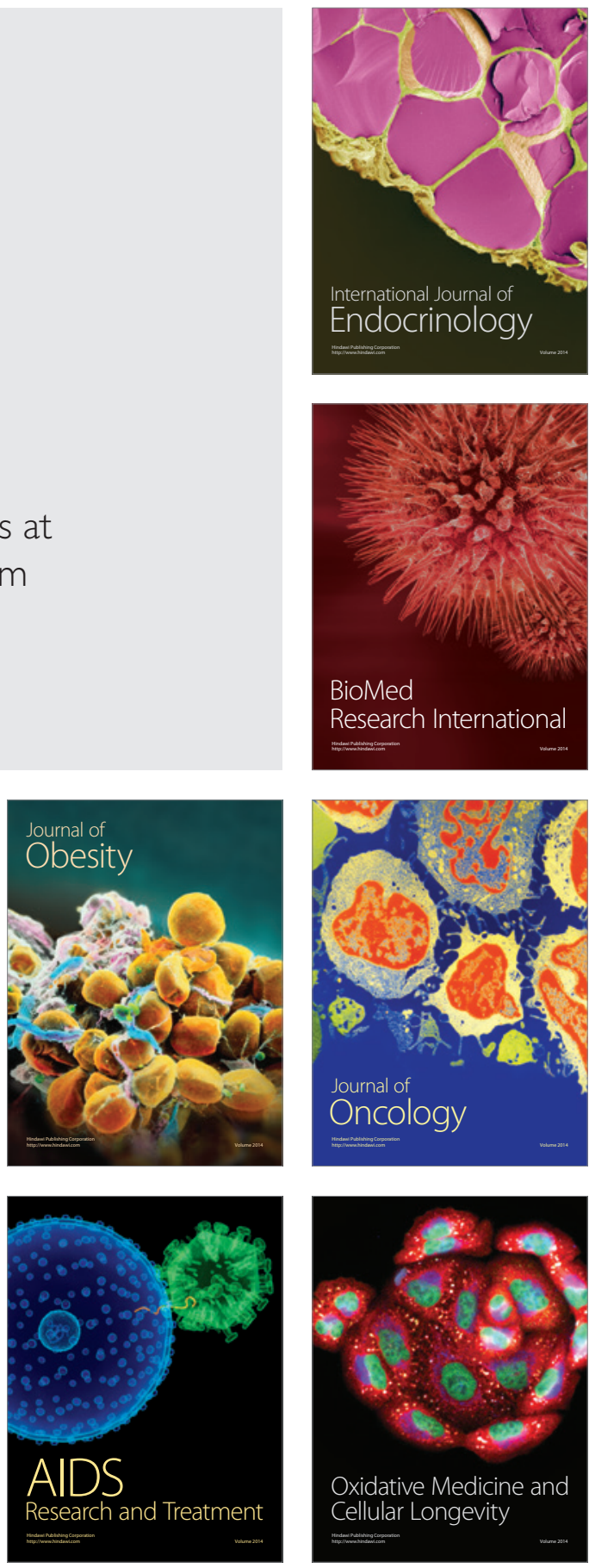